\title{
Author Correction: Improving Substrate Consumption and Decrease of Growth Yield in Aerobic Cultures of Pseudomonas denitrificans By Applying Low Voltages in Bioelectric Systems
}

Luis F. Cházaro-Ruiz ${ }^{1}$ - María Irene López-Cázares ${ }^{1}$ - Ignacio González ${ }^{2}$ - Yanet Toriz ${ }^{1}$. Felipe Alatriste-Mondragon ${ }^{1} \cdot$ Marcela Santana $^{1} \cdot$ Lourdes B. Celis $^{1}$

Published online: 6 December 2019

(C) Springer Science+Business Media, LLC, part of Springer Nature 2019

Author Correction: Applied Biochemistry and Biotechnology

https://doi.org/10.1007/s12010-019-03168-x

The original version of this article unfortunately contained a mistake in Equation 1. The equation 1 should be presented as:

$$
Y_{\mathrm{obs}}=\left(X_{\mathrm{t}}-X_{0}\right) /\left(S_{0}-S_{t}\right)
$$

The online version of the original article can be found at https://doi.org/10.1007/s12010-019-03168-x

Luis F. Cházaro-Ruiz

luis.chazaro@ipicyt.edu.mx

Lourdes B. Celis

celis@ ipicyt.edu.mx

1 División de Ciencias Ambientales, Instituto Potosino de Investigación Científica y Tecnológica, Camino a la Presa San José 2055, Lomas 4a. Sección, San Luis Potosí, S.L.P, C.P.78216 México, Mexico

2 Departamento de Química, Universidad Autónoma Metropolitana - Iztapalapa, Apdo. Postal 55-534, 09340, 09340 México City, Mexico 